\title{
¿Por qué cambió la legislación aduanera en el Perú?
}

José Antonio La Noire NúÑez

Doctor en Derecho por la Universidad Nacional Federico Villarreal. Máster en Derecho Aduanero por la Universidad Nacional Federico Villarreal.

Licenciado en Administración por la Universidad de Lima. Agente de Aduana Titulado por el Instituto de Desarrollo Tributario y Aduanero. Profesor Universitario a tiempo parcial en la Universidad Nacional Mayor de San Marcos y en la Universidad Le Cordon Bleu.

SUMARIO:

I. Introducción.

II. Problemática de los operadores de comercio exterior.

1. El agente de aduana.

2. El agente de carga internacional.

III. Marco legal internacional que regula a los sujetos de la obligación aduanera.

IV. Conclusiones. 


\section{RESUMEN:}

El autor a través de este artículo pretende poner en conocimiento al lector sobre la reforma aduanera producida en el Perú durante los años 2015-2020. Dicha reforma significó, por un lado, una mejora en nuestra legislación nacional al regular la Administración Aduanera de manera más eficiente a todos los Operadores de Comercio Exterior y, por otro lado, una modernización en el servicio aduanero brindado al aplicar sistemas de gestión de calidad y seguridad que permitan gestionar despachos aduaneros de manera más ágil y simplificada, asegurar la trazabilidad completa de la carga y reducir costos finales.

Palabras clave: Reforma aduanera, operadores de comercio exterior, sistemas de gestión.

\footnotetext{
ABSTRACT:

Through this article, the author intends to inform the reader about the customs reform which took place in Peru between 2015 and 2020. Such reform, on one hand meant an improvement in our national legislation as the Customs Administration regulated more efficiently the foreign commerce operators and; on the other hand, implied a modernization in the customs service, applying quality and security systems that allow managing customs clearances in a more agile and simplified way, also ensuring full traceability of cargo and reducing final costs.

Keywords: Customs reform, foreign trade operators, management systems.
}

\section{INTRODUCCIÓN}

A través de la publicación del Decreto Legislativo 1433 y del Decreto Supremo No $367-2019$, se modificaron la Ley General de Aduanas y su Reglamento, respectivamente. En el caso de la Tabla de Sanciones, mediante el Decreto Supremo $\mathrm{N}^{\circ}$ 418-2019-EF se derogó la Tabla anterior y se aprobó una nueva; y mediante Resoluciones de Superintendencia se modificaron o aprobaron nuevas versiones de los procedimientos de los regímenes aduaneros de importación, exportación, perfeccionamiento, depósito aduanero, tránsito, especiales o de excepción; así como el procedimiento de autorización y categorización de operadores de comercio exterior, todo ello durante todo el año 2020 y en plena pandemia.

Ahora bien, la pregunta que cae de madura sería: "¿y por qué?" o "ipor qué se produjeron tantos cambios consecutivos en tan poco tiempo?", y la respuesta es porque el Perú debía modernizar su legislación aduanera para cum- plir con: las medidas adoptadas en el Acuerdo de Facilitación de la Organización Mundial de Comercio - OMC; el Programa de Facilitación Aduanera, Seguridad y Transparencia - FAST desarrollado por la Superintendencia Nacional de Aduanas y de Administración Tributaria SUNAT; y los paquetes de medidas lanzados por el gobierno para mejorar la competitividad en el comercio exterior peruano, entre otras.

Para tal fin, la Administración Aduanera debía revisar los procesos de ingreso, permanencia, traslado y salida de las mercancías hacia y desde el territorio aduanero', así como regular de manera más eficiente a todos los Operadores de Comercio Exterior - OCE en aspectos referidos a sus condiciones de autorización y montos de garantías ${ }^{2}$, a su medición del nivel de cumplimiento para obtener la categoría ${ }^{3}$, y a su renovación o revocación, debido a que:

"El OCE es el primer contacto con el ciudadano interesado en realizar operaciones de

1. Decreto Legislativo 1053, Ley General de Aduanas, artículo 1.

2. Decreto Supremo No 367-2019-EF, Modifican el reglamento de la Ley General de Aduanas, Anexos 1 y 4.

3. DESPA-PG.24 -Versión 4-, Autorización y Categorización de Operadores de Comercio Exterior, Anexo I. Reglas para la Categorización. 
comercio exterior. Una vez contratado, el OCE debe guiar a su cliente en las actividades necesarias pare cumplir con su objetivo y al mismo tiempo asegurar que cumpla con la normativa aduanera aplicable. Por tanto, la actividad del OCE es parte constitutiva del servicio aduanero y debe tender a alcanzar los niveles establecidos en las normas internacionales sobre sistemas de gestión de la calidad, con énfasis en los procesos, y a aplicar estándares internacionales elaborados por organismos internacionales vinculados al comercio exterior".4

\section{PROBLEMÁTICA DE LOS OPERADORES DE COMERCIO EXTERIOR}

Según información de la SUNAT al 2017 sobre los OCE autorizados, tenemos un total de 1557 operadores, de los cuales una gran cantidad "no sólo no cumplía su rol a cabalidad, sino que mostraban reiterados problemas en la calidad de los servicios que prestaba a sus clientes, generando demoras, sanciones, riesgos y sobrecostos". ${ }^{5}$ Dicho de otra manera, el antiguo procedimiento de Autorización y Acreditación de Operadores ${ }^{6}$ sólo evidenciaba la orientación al cumplimiento de requisitos y obligaciones formales, y no contemplaba la implementación de un sistema de gestión de calidad para su autorización, ni tenía en consideración el contacto directo que tienen con el importador y/o exportador, con la carga y su consecuente seguridad y trazabilidad.

Por ello, la Administración Aduanera optó por aplicar mayores controles para con sus administrados al reevaluar aspectos referidos a su autorización, obligaciones, infracciones y sanciones, así como la aplicatoriedad de los regímenes de gradualidad e incentivos, pues es la misma Administración quien los autoriza y ahora categoriza dependiendo de su desempeño. Es decir, se ha evaluado a los OCE y se ha propuesto un nuevo modelo para su acreditación, puesto que ahora la SUNAT sólo va a trabajar con aquellos operadores que cuenten con un servicio de calidad, transparente y seguro; con un portal web corporativo ${ }^{7}$ y con estándares internacionales que permitan darle trazabilidad a toda la cadena logística. ${ }^{8}$ De esta forma, los OCE durante el proceso de despacho de mercancías estarían demostrando, en todo momento, un alto nivel de cumplimiento de la legislación aduanera nacional.

A continuación, se presenta el Cuadro 01, en donde se presentan a los 1557 OCE autorizados al 2017 mencionados en el párrafo de arriba, pero clasificados por cada tipo de operador:

\section{Cuadro 01: OCE autorizados al 2017}

\section{TIPOS DE OCE}

1 Despachadores de Aduanas

1.1 Agentes de Aduanas

1.2 Entidades Públicas

1.3 Dueños o Consignatarios

1.4 Entidades Benéficas

2 Agentes de Carga Internacional

3 Transportistas o su Representante en el País

3.1 Líneas Aéreas

3.2 Agencias Marítimas y Fluviales

4 Almacenes Aduaneros

5 Empresas de Servicio de Entrega Rápida

6 Beneficio de Material para Uso Aeronáutico

7 Empresa de Servicio Postal (SERPOST)

8 Almacén Libre (duty free)
SUBTOTAL TOTAL 428 
Es importante resaltar que, de los 1557 operadores autorizados por la Administración Aduanera, una parte considerable de ellos se agrupa en 02 operadores: los Agentes de Aduana - AA y los Agentes de Carga Internacional - ACl, de los cuales vamos a hablar y desarrollar su problemática en los siguientes títulos.

\section{El agente de aduana.}

Actualmente ya no encontramos una definición en la legislación aduanera sobre la figura del Agente de Aduana, pero sí ubicamos en el artículo 19, inciso a) de la Ley General de Aduanas - LGA, Decreto Legislativo 1053, una definición de la categoría de operador a la cual pertenece y con el artículo 129 de la LGA, podemos desarrollar una definición sobre la base de su función y naturaleza jurídica de la siguiente forma: "El AA, como despachador de aduana, se encarga de gestionar los despachos aduaneros encomendados por el dueño, consignatario o consignante de la mercancía mediante un mandato con representación que lo acepta por cuenta y riesgo de aquellos". No obstante, previamente debía cumplir con una serie de requisitos para su autorización como OCE en temas sobre: infraestructura, patrimonio, constitución y renovación de garantías, conservación de documentos, acreditación de personal y una serie de obligaciones sine qua non.

Lamentablemente, con la sola mención de esos requisitos no estamos explicando la problemática de los $A A$, sino hasta ver las esta- dísticas del comportamiento del mercado de agenciamiento aduanero y su cuota de mercado. Para citar algunas cifras, vamos a irnos de un extremo a otro; por un lado, tenemos que durante el año 2017 el 10\% — 35 AA-gestionaron más del $55 \%$ de despachos aduaneros numerados bajo el régimen de importación para el consumo a nivel nacional; y por el otro lado, el 83.1\% - 291 AA - tramitaron el 36.2\% de los despachos aduaneros. ${ }^{9}$ El otro $6.9 \%$ restante - $24 \mathrm{AA}$ - se ubicaría en el medio de estos dos extremos, realizando el $9.7 \%$ de despachos faltantes.

Es decir, los primeros 59 despachadores - $16.9 \%$ - concentran el $64.7 \%$ del total de Declaraciones Aduaneras de Mercancías - DAM numeradas bajo el régimen de importación para el consumo, el cual representa el $80 \%$ del movimiento comercial peruano en valor CIF. El problema radica en que 291 AA se disputan el $20 \%$ restante del movimiento comercial peruano; y es ahí en donde empiezan los problemas, porque el índice de incidencia en los despachos aduaneros de este último grupo es realmente alto: cerca de 36 de cada 100 DAM tienen alguna incidencia en la tramitación del régimen durante el control concurrente y solamente 133 AA han seguido gestionando despachos aduaneros de manera interrumpida en periodo 2003-2017. ${ }^{10}$ Otros datos curiosos por mencionar son que, a diferencia de otros OCE, el AA es el único operador que no necesita una autorización previa por parte de una entidad distinta de la SUNAT, aunque es el único operador que

4. Exposición de Motivos del Decreto Legislativo 1433, A.1. Generalidades.

5. Exposición de Motivos del Decreto Legislativo 1433, A.1. Generalidades.

6. INTA-PG.24 -Versión 2-, Autorización y Acreditación de Operadores de Comercio Exterior, Anexo I. Reglas para la Categorización.

7. Decreto Supremo № 367-2019-EF, Modifican el reglamento de la Ley General de Aduanas, VII. Descripción.

8. Exposición de Motivos del Decreto Legislativo 1433, 1. Operadores y régimen sancionador.

9. Exposición de Motivos del Decreto Legislativo 1433, A.2.1. Agentes de Aduana.

10. Exposición de Motivos del Decreto Legislativo 1433, A.2.1. Agentes de Aduana. 
tanto su representante legal como sus auxiliares de despacho"1 deben estudiar y rendir un examen en el Instituto Tributario Aduanero de la SUNAT o hechos como que un solo AA podría ser representante legal de todas las agencias de aduana - persona jurídica-.

Por ello, la Administración Aduanera ha visto conveniente implementar un sistema de categorización de los $\mathrm{OCE}$, en donde el récord de infracciones y sanciones va a determinar la categorización y renovación de su autorización, bajo un sistema de gestión de calidad, con énfasis en los procesos del servicio aduanero brindado y cumpliendo con estándares internacionales. Cabe señalar que todos los operadores hasta antes de las 2 últimas modificaciones de la LGA y su reglamento, tenían una autorización con vigencia indefinida, con la única exigencia de que anualmente debían renovar una garantía a favor de la SUNAT.

En otro orden de ideas, nadie va a negar que la actividad del AA es parte constitutiva del servicio aduanero peruano y debe tender a alcanzar niveles internacionales de calidad y seguridad en toda la cadena logística. Para ello, se establecían las anteriores obligaciones del despachador, que se encontraban en los artículos 16 al 19 de la LGA, y su propia definición y obligaciones específicas en el Subcapítulo III, Capítulo I, Título II, Sección Segunda de la LGA. Sin embargo, tal base legal estuvo vigente hasta antes de la entrada en vigor del Decreto Legislativo 1433 publicado en septiembre de 2018. En otras palabras, ya no existen obligaciones específicas por operador, ni siquiera hay una definición específica del AA, menos los requisitos de $50 \mathrm{~m}^{2}$ de infraestructura y de los USD 50,000 de acreditación de patrimonio, ni la conservación de documentos por 5 años ni la autenticación de documentos, pero lo que sí existe ahora es la exclusividad de 1 representante aduanero por operador.

En el caso del Reglamento de la Ley General de Aduanas - RLGA, aprobado por el Decreto Su- premo $\mathrm{N}^{\circ}$ 010-2009-EF y que fue recientemente modificado por el Decreto Supremo $N^{\circ} 367-$ 2019-EF, publicado en diciembre de 2019, nos trae otras varias novedades, tales como: el AA no es más un auxiliar de la función pública; la solicitud para su autorización es a través de una declaración jurada electrónica, en donde debe cumplir con ciertas condiciones de los Anexos del RLGA; se le autoriza por un plazo máximo de tres años y se le categoriza en categoría " $A$ ", " $B$ " o C"; dependiendo del nivel de cumplimiento de su desempeño durante el año, solo a los operadores que se encuentren en la categoría " $A$ " y "B" se les renovará la autorización para operar. Todo lo antes dicho, se encuentra actualmente en el Capítulo II, Título II, Sección Segunda del RLGA.

Estas modificaciones recién presentan un avance en lo que se refiere a una mejora continua y a la adopción de normas internacionales de gestión; diferente de las modificaciones al RLGA publicadas en junio en el Decreto Supremo $N^{\circ} 163-2016$, cuando sólo se eliminaba el carné de OCE y se permitía que un extranjero sea representante legal de un AA acreditado por la SUNAT como despachador de aduana.

Por cierto, es un poco complicada la primera lectura de la LGA y su reglamento, pues el lector se va a encontrar con una serie de artículos faltantes dentro de la legislación aduanera peruana y eso se debe a que durante los últimos 5 años se han aprobado diversas normas modificatorias, pero actualmente no existe un Texto Único Ordenado de dichas leyes para que cada artículo tenga una numeración correlativa. Dicho esto, en cuanto al RLGA tenemos que mediante Decreto Supremo $N^{\circ} 367-2019-E F$ se derogaron los artículos del 29 al 58, el 193, del 196 al 198, del 250 al 252, el 254 y el anterior anexo; y con el Decreto Supremo No 163-2016-EF, también fueron derogados los artículos del 169 al 183, además de los artículos 11 y 58 del RLGA, aunque posteriormente con el Decreto Supremo № 367-2019-EF se reincorporó un nuevo ar-

11. IATA-PE.04, procedimiento especifico acreditación de capacitación del personal auxiliar de despacho, VI. Disposiciones Generales 
tículo 11. Por otra parte, tenemos a la LGA que mediante Decreto Legislativo 1433 publicado el año 2018 se le eliminaron los artículos 14, del 28 al 46 y del 201 al 204; además de modificar una serie de definiciones de los OCE del artículo 2 para reincorporarlos en el artículo 19 de la actual Ley. De la misma forma, el Decreto Legislativo 1235 publicado el año 2015 derogó los artículos del 111 al 128.

\section{El agente de carga internacional}

Para referirnos a este operador vamos a usar su antigua definición, la cual se encontraba en las definiciones del artículo 2 de la LGA, definido como:

"persona que puede realizar y recibir embarques, consolidar, y desconsolidar mercancías, actuar como operador de transporte multimodal sujetándose a las leyes de la materia y emitir documentos propios de su actividad, tales como conocimientos de embarque, carta de porte aéreo, carta de porte terrestre, certificados de recepción y similares".

Sin embargo, actualmente esta definición nos trae una seria de dudas respecto sobre si se trata de una persona natural o jurídica; además, no debemos olvidar que esta definición ya no es la vigente, porque de esta definición la LGA autorizó a un nuevo operador: "el Operador de Transporte Modal Internacional". En ese orden de ideas, tenemos que la actual LGA en su artículo 15 nos indica que los OCE pueden ser persona natural o jurídica, y también el Decreto Supremo $N^{\circ}$ 025-2019-MTC, que modificó el artículo 72 e incorporó los artículos 72-A y 72-B al Reglamento de la Ley 28583, Ley de Reactivación y Promoción de la Marina Mercante Nacional y modificada por la Ley 29475, aprobado por Decreto Supremo N 0142011-MTC, abrió esa posibilidad de ser persona natural para la autorización de los Agentes de Carga Internacional. Para ello, deberá además de haber efectuado el pago por derecho de trámite de certificación del operador ante el Ministerio de Transportes y Comunicaciones - MTC, acreditar que cuenta con un patrimonio mínimo de USD 50,000 o su equivalente en moneda nacional; y adicional a ello, la presentación de una póliza de seguros de riesgos no menor de USD 50,000.

Para el caso de los $\mathrm{ACl}$, se debe tramitar una autorización previa a su acreditación como OCE ante SUNAT. ${ }^{2}$ Dicho trámite era antiguamente expedido sólo a personas jurídicas y tramitado en el MTC ante 2 de sus distintas direcciones; por la vía marítima, ante la Dirección General de Transporte Acuático - DGTA y por la vía aérea, ante la Dirección General de Aeronáutica Civil — DGAC. Si dicho operador tramitaba su certificado en la DGTA — de manera gratuita—, podía presentar su certificado marítimo del MTC, su licencia de funcionamiento y llenar unos formatos del derogado DESPA-PG-24 - Versión 3- ante la SUNAT y ser autorizado como OCE en la jurisdicción de la Aduana Marítima del Callao.

En suma, ante ambas Direcciones no había que presentar ninguna garantía, sino la simple presentación de una solicitud adjuntando una serie de documentos, como eran: copia de la constitución de la empresa, copia literal, vigencia de poderes, ficha RUC, copia del documento de identidad o carné de extranjería del representante legal y que figure de manera expresa en el objeto social de la empresa, que va a desempeñar funciones de $\mathrm{ACl}$ por la vía marítima. En el caso de la vía aérea, además de lo mencionado para la vía marítima, se pide que un trabajador del operador haya llevado 2 cursos, uno de Mercancías Peligrosas - 40 horas - y el otro de Procesos de Carga - 16 horas-; además de contar con un certificado de Conformidad de Operación, debe haber implementado dentro del operador manuales y otras disposiciones técnicas de acuerdo con las Regulaciones Aeronáuticas del Perú - RAP sobre ACl Acreditado -RAP 109-y sobre Transporte de Mercancías Peligrosas por Vía Aérea — RAP 110—.

12. Decreto Supremo No 367-2019-EF, Modifican el reglamento de la Ley General de Aduanas, Anexo 1.A. Autorizaciones Previas. 
Si bien es cierto que este paso previo ante el MTC se mantiene, su definición sí cambió y la encontramos en el artículo 19, inciso d) de la LGA como: "es el que realiza y recibe embarques, consolida y desconsolida mercancías y emite documentos propios de su actividad, que cuenta con la autorización de la entidad pública correspondiente." Asimismo, antes de las modificatorias a la ley, se contemplaban obligaciones específicas y requisitos documentarios y de infraestructura en los artículos 29, 36 y 37 de la LGA. Con los cambios producidos a la LGA y su reglamento, en los años 2018 y 2019, respectivamente, vemos que al igual que con los $A A$, se les ha eliminado los mencionados requisitos de infraestructura y ya no necesitan de un área no menor de $20 \mathrm{~m}^{2}$ para realizar sus actividades; sin embargo, siguen necesitando contar con un local físico porque para ser certificados ante el MTC, se les exige una copia de la licencia municipal de funcionamiento.

Por otro lado, vemos que actualmente existe la obligatoriedad de constituir una garantía a favor de la SUNAT para ser autorizados como OCE; este punto fue corregido en el primer paquete de medidas que lanzó el gobierno el año 2017 para mejorar la competitividad del comercio exterior, porque no podía ser posible que el RLGA indicara en su artículo 19 que todos los OCE debían constituir una garantía a favor de la SUNAT y el ACl fuera el único que no presentara garantía alguna. Por ello, y por lo visto en el Cuadro 01 del presente, entendemos que había que disminuir a esos $738 \mathrm{ACl}$-que representaban casi el 50\% del universo de todos los OCE autorizados - con la presentación de una póliza de seguros y acreditar un patrimonio ante el MTC por un total no menor de USD 100,000 y ante la SUNAT, constituir una garantía por el importe de USD 25,000 si se encontrara en la categoría "A" o de USD 37,500 si se encontrara en la categoría "B".13 Cabe destacar que para pertenecer a la categoría " $\mathrm{A}$ " los OCE deben mantener un nivel de cumplimiento mayor o igual a $90 \%$ y para la categoría "B", un nivel de cumplimiento mayor o igual a $60 \%$ y menor a $90 \% .{ }^{14}$ Los operadores que se encontrasen en la categoría " $\mathrm{C}$ " — desempeño menor a $60 \%$ serían cancelados.

De igual forma, la derogada Tabla de Sanciones - TS aplicables a las Infracciones previstas en la Ley General de Aduanas, aprobada por Decreto Supremo $N^{\circ}$ 031-2009-EF no contemplaba dentro de su prelación de sanciones ni la suspensión ni la cancelación para el operador, sino sólo la aplicación de 3 sanciones con multa por un valor máximo 1 UIT, y con el beneficio de que a ello se aplicaba el régimen de incentivos y gradualidad. Por tal motivo, la actual TS, aprobada por Decreto Supremo N ${ }^{\circ} 418-2019-E F$ y entrada en vigencia el primero de enero de 2020, ahora tipifica la mayoría de los supuestos de infracción del operador con gravedad leve, pero también lo sanciona con gravedad "grave" cuando no se ha adecuado o mantiene las condiciones " $\mathrm{B}$ " $\mathrm{y}$ " $\mathrm{C}$ " del Anexo 1 del RLGA. Para seguir con la antigua prelación de la TS, tenemos que ya se suspende al operador si no ha constituido una garantía a favor de la SUNAT e inclusive se cancela si no se ha adecuado o implementado a las condiciones " $\mathrm{D}$ " del Anexo 1 del RLGA.

En los párrafos precedentes, hemos seguido el proceso legal del perfeccionamiento de la figura del $\mathrm{ACl}$ en estos últimos 5 años; sin embargo no debemos de dejar de lado las estadísticas de los $750 \mathrm{ACl}$ acreditados al 2017, que al igual que los $A A$, trae muchas sorpresas y eso se debía, en gran medida, a los vacíos legales que hemos desarrollo en los párrafos anteriores. Ahora bien, estadísticamente tenemos que del total

13. Decreto Supremo No 367-2019-EF, Modifican el reglamento de la Ley General de Aduanas, Anexo 4. Tabla de Garantías.

14. Decreto Supremo № 367-2019-EF, Modifican el reglamento de la Ley General de Aduanas, Artículo 19. Categorías del OCE. 
de $750 \mathrm{ACl}$ autorizados al 2017, los primeros 25 de ellos representan el $51.4 \%$ de total de manifiestos consolidados y desconsolidados; es decir, aunque esos $25 \mathrm{ACl}$ sólo representen al $3.6 \%$ del total, ellos tramitan más del $50 \%$ de la operatividad peruana en el sector de agenciamiento de carga. ${ }^{15}$

Otro dato, bastante inquietante, es que $254 \mathrm{ACl}$ no realizaron ningún tipo de envío de manifiesto aun cuando estaban autorizados para operar; es decir, el $33.87 \%$ no realizó operatividad alguna durante el mismo periodo. Para concluir, tenemos que el otro $49.6 \%{ }^{16}$ de la operatividad se divide entre $471 \mathrm{ACl}$, y es este grupo el que concentra casi el $50 \%$ de sanciones aplicadas por SUNAT.

\section{MARCO LEGAL INTERNACIONAL QUE RE- GULA A LOS SUJETOS DE LA OBLIGACIÓN ADUANERA}

La Potestad Aduanera es el conjunto de facultades y atribuciones que tiene la Administración Aduanera para regular el ingreso, permanencia, traslado y salida de mercancías, personas y medios de transporte. ${ }^{17}$ Dentro del ejercicio de esa potestad, está la ejecución de acciones de control de las mercancías, antes y durante el despacho de las mercancías, con posterioridad a su levante o antes de su salida del territorio Aduanero. ${ }^{18}$
Mencionado lo anterior, vemos que no solo las mercancías se encuentran sometidas a control Aduanero, sino también las personas que intervienen directa o indirectamente en las operaciones de comercio exterior ${ }^{19} ; y$ todo ese control se basa en los principios generales de la LGA, de los cuales vamos a desarrollar 3 principios. El primer principio es el de "Facilitación del Comercio", en donde se afirma que los servicios aduaneros son esenciales y están destinados a facilitar el comercio exterior, a contribuir al desarrollo nacional y a velar por el control aduanero y el interés fiscal ${ }^{20}$; el segundo principio es el de "Participación de Agentes Económicos", en donde el Estado promueve la participación de los agentes económicos en la prestación de los servicios aduaneros, mediante la delegación de funciones al sector privado ${ }^{21}$; y por último, el principio de "Gestión de la calidad y uso de estándares internacionales", que igual lo encontramos parafraseado en Disposiciones General del RLGA, cuando se señala que los servicios aduaneros deberán tender a alcanzar los niveles establecidos en las normas internacionales sobre sistemas de gestión de la calidad con énfasis en los procesos ${ }^{22}$, así como promover la digitalización de procesos a cargo de las entidades públicas y privadas que forman parte de la cadena logística ${ }^{23}$ para transparentar operaciones y disminuir costos de transacción en el marco de la emergencia sanitaria por la COVID-19, entre otras medidas.

15. Exposición de Motivos del Decreto Legislativo, A.2.4. Agencias de Carga Internacional.

16. Exposición de Motivos del Decreto Legislativo, A.2.4. Agencias de Carga Internacional.

17. Decreto Legislativo 1053, Ley General de Aduanas, artículo 164.

18. Decreto Legislativo 1053, Ley General de Aduanas, artículo 165.

19. Decreto Legislativo 1053, Ley General de Aduanas, artículo 162.

20. Decreto Legislativo 1053, Ley General de Aduanas, artículo 4.

21. Decreto Legislativo 1053, Ley General de Aduanas, artículo 6.

22. Decreto Legislativo 1053, Ley General de Aduanas, artículo 7.

23. Decreto Legislativo 1492, que aprueba disposiciones para la reactivación, continuidad y eficiencia de las operaciones vinculadas a la cadena logística de comercio exterior. 
Sobre estos principios firmemente se basa el comercio exterior peruano, el cual se desarrolla en un escenario en constante cambio, en donde: la formación de bloques económicos y la firma de los Tratados de Libre Comercio - TLC-; la implementación del Acuerdo sobre Facilitación del Comercio - AFC - de la Organización Mundial de Comercio - OMC - vigente en el Perú desde el 22 de enero del año 2017; la puesta en marcha del programa de Facilitación Aduanera, Seguridad y Transparencia -FASTpor SUNAT desde fines del año 2018; y la guía para la medición del tiempo requerido para el despacho de las mercancías y el Marco de Norma SAFE versión 2018, ambas publicadas por la Organización Mundial de Aduanas - OMA - el año 2011 y 2018, respectivamente, han modificado no sólo la forma en la que hacemos negocios, sino también el ejercicio de la potestad aduanera con el uso obligatorio de sistemas de gestión de calidad para no retrasar los tiempos de despacho en el control concurrente, sino para ejercer su control en los controles previos y posteriores y así, mejorar el desempeño de toda la distribución física internacional.

En este escenario, en donde la constante es el cambio, el Gobierno como agente facilitador del comercio lanza un Primer Paquete de medidas en el año 2017 para mejorar la competitividad en el comercio exterior peruano fijando 5 objetivos: "mejorar la operatividad aduanera, incrementar la competitividad de servicios logísticos, crear mecanismos de coordinación interinstitucional, fomentar la simplificación administrativa y promocionar inversiones productivas" ${ }^{\prime 24}$; a través de la implementación de 13 medidas, entre las cuales destacan ${ }^{25}$ :

a) Un incentivo para el uso del despacho an- ticipado, en donde la garantía que se establece para los AA no considerará en su cálculo los despachos anticipados realizados, solo los despachos diferidos;

b) La agilización del despacho diferido, en donde se permitirá la numeración de la declaración aduanera desde la llegada de la mercancía al puerto, sin esperar el término de la descarga del buque;

c) La ampliación del alcance del embarque directo de exportación, en donde se permitirá a los exportadores que cuentan con calificación de Operador Económico Autorizado $^{26}$ - OEA - que puedan enviar sus mercancías de exportación directamente desde su local al puerto sin pasar por un depósito temporal;

d) Los AA podrán realizar operaciones en jurisdicciones distintas a aquella donde obtuvieron, en donde el AA que cuente con estándar de OEA pueda realizar operaciones a nivel nacional;

e) La mejora de la regulación de los $\mathrm{ACl}$, con lo cual se reducirá la informalidad en el sector a través de la exigencia de requisitos mínimos sobre garantías y patrimonio, así como el establecimiento de sanciones en caso no se cumpla con la regulación;

f) El fomento del uso del Exporta Fácil, en donde se ampliará el valor de las mercancías de USD 5,000 a USD 7,500 que pueden emplear el sistema mencionado, sin AA y bajo un procedimiento simplificado;

g) La implementación del observatorio de logística de comercio exterior, en donde MINCETUR creará una plataforma electrónica dentro de la Ventanilla Única de Comercio Exterior - VUCE- con información de tarifas de los servicios logísticos de comercio exterior, denominado como

24. "Gobierno anuncia trece medidas para mejorar la competitividad del comercio exterior", en MINCETUR, acceso el 9 de julio de 2021, https://www.mincetur.gob.pe/gobierno-anuncia-trece-medidas-para-mejorar-la-competitividad-del-comercio-exterior/

25. Ibíd.

26. DESPA-PG.29 - Versión 2-, Certificación del Operador Económico Autorizador, Anexo 1. Facilidades. 
Módulo de Información sobre Servicios de Logística de Comercio Exterior - MISLOen donde los primeros operadores obligados a su implementación son los AA. ${ }^{27}$

Siguiendo con este escenario de cambios, el MINCETUR lanzó un Segundo Paquete de medidas para mejorar la competitividad del sector Comercio Exterior mediante la promulgación de la Ley 30823 publicada el 18 de julio de 2018, en la que se estableció el marco de la delegación de facultades al Poder Ejecutivo para legislar sobre distintas materias; entre ellas, sobre materia de gestión económica y competitividad en el inciso d), numeral 2), artículo 2 de la mencionada ley, en donde el Ejecutivo podrá:

"Actualizar el Decreto Legislativo 1053, Ley General de Aduanas, y la Ley 28008, Ley de los Delitos Aduaneros, a fin de adecuarlas a estándares internacionales, agilizar el comercio exterior y hacer eficiente la seguridad de la cadena logística y preservarla, incluyendo aspectos de recaudación, obligación tributaria aduanera y sistema de infracciones, cautelando el respeto a los compromisos internacionales asumidos por el Estado peruano".

Así pues, mediante el Decreto Legislativo 1433, publicado el 16 de setiembre de 2018 en el Diario Oficial El Peruano, se modificó la LGA. Entre los cambios más relevantes tenemos:

a) Los nuevos requisitos y obligaciones exigibles a los operadores de Comercio Exterior -OCE-, Operadores Intervinientes Ol-y Terceros —artículos del 15 al 27-;

b) La incorporación y definición de la figura del representante aduanero - artículo 23;

c) El nueva numeración del mandato en la Ley -artículo 129-;

d) Los nuevos plazos para la destinación aduanera y casos especiales -artículos 130 y 132 -

e) Los nuevos plazos para la exigibilidad de la obligación tributaria aduanera —artículo 150一;

f) Los plazos de prescripción de la obligación tributaria aduanera -artículo 155-;

g) La eliminación del mínimo de $4 \%$ de reconocimientos físicos en el empleo de la gestión del riesgo - artículo 163-;

h) Las causales de abandono legal —artículo 178-;

i) Las infracciones y sancionables aplicables a los OCE, Ol y Terceros - Sección Décima-.

De igual forma, mediante el Decreto Supremo $N^{\circ}$ 367-2019-EF, publicado el 09 de diciembre de 2019 en el Diario Oficial El Peruano, se modificó el RLGA. Si bien es cierto que en las Disposiciones Complementarias Finales de la referida norma se condiciona la entrada en vigor de la adecuación a los requisitos y condiciones para los OCE establecidos en el artículo 17 y el Anexo 1 del RLGA para el 31 de diciembre de 2021, casi la totalidad de las modificatorias a la norma ya está vigente. Entre los cambios más relevantes tenemos:

a) Los nuevos requisitos exigibles a los Operadores de Comercio Exterior - OCE-, Operadores Intervinientes - Ol-y Terceros - artículos 9 al 28 y anexos finales-;

b) En qué regímenes aduaneros el mandato electrónico es obligatorio - artículo 185-;

c) La modalidad de despacho anticipado obligatorio y sus excepciones -Artículo 62A-;

d) La entrega y traslado de la mercancía - artículo 150-;

e) Otros operadores facultados a efectuar despachos aduaneros —artículo 184-;

f) Lineamientos para aplicar sanciones y supuestos no sancionables -artículos 248 y 249-.

En el caso de la TS, no hubo tales modificaciones, sino que mediante el Decreto Supremo $\mathrm{N}^{\circ}$ 418-2019-EF, publicado el 31 de diciembre de 2019 en el Diario Oficial El Peruano, se dero-

27. Resolución Ministerial No 182-2020-MINCETUR, Incorporan Operadores en el Módulo de Información sobre los Servicios de Logística de Comercio Exterior - MISLO, Artículo 1 
gó la TS anterior y se aprobó una nueva norma, que es muy diferente de su predecesora norma y en donde encontramos las siguientes novedades:

a) Se clasifica la gravedad del supuesto de infracción del sujeto de la obligación aduanera en "leve", "grave" o "muy grave", en donde inclusive se les exime de sanción por infracciones "leves" dependiendo de la categoría del operador y/o si es OEA;

b) Se codifica la infracción para los OCE con "N", con "P" para los Ol y con " $\mathrm{T}$ " para los Terceros;

c) Se fija la cuantía de la sanción, se individualiza al infractor y se desarrollan excepciones para su aplicación;

d) Desaparece la estructura de la prelación de sanciones de la TS anterior, que iba desde multa, suspensión, cancelación hasta inhabilitación; y se reestructura la TS bajo 5 numerales:

(i) infracciones de los OCE,

(ii) infracciones de los $\mathrm{Ol}$,

(iii) infracciones de los Terceros,

(iv) infracciones sancionables con comiso; $y$,

(v) consideraciones adicionales.

En el caso de los OCE las infracciones van relacionadas al no cumplimiento, mantenimiento o adecuación de: autorizaciones, manifiesto y actos relacionados, declaraciones, otras informaciones, controles aduaneros y seguridad.

Como último punto, tenemos el Acuerdo sobre Facilitación del Comercio - AFC-, que es un acuerdo multilateral de la OMC adoptado en diciembre de 2013 y ratificado por el Perú mediante Decreto Supremo $N^{\circ}$ 044-2016-RE bajo el nombre de "Protocolo de Enmienda del Acuerdo de Marrakech" por el que se establece la Organización Mundial de Comercio, el cual entró en vigencia en el Perú en febrero de 2017 mediante el Decreto Supremo No
002-2017-MINCETUR, e incorpora el AFC en el Anexo $1 \mathrm{~A}$ del acuerdo sobre la OMC. En el mencionado acuerdo se aclaran y mejoran algunos artículos del GATT de 1994, el cual consta de veinticuatro artículos distribuidos en 3 Secciones. Solamente vamos a desarrollar 2 artículos de la Sección I, con el propósito de explicar cómo se ha agilizado el despacho de las mercancías, porque los demás artículos tratan sobre resoluciones anticipadas, la libertad de tránsito y la cooperación aduanera.

La Sección I contiene los primeros 12 artículos del acuerdo, que recogen las recomendaciones de la OMA y del Convenio de Kyoto Revisado - Convenio Internacional para la Simplificación y Armonización de los Regímenes Aduaneros entrado en vigencia el año 2006-. Ahora bien, vamos a mencionar el artículo 7, que desarrolla las medidas necesarias para agilizar el "levante y despacho de las mercancías" en 9 puntos, referidos a:

a) La tramitación previa a la llegada de las mercancías para agilizar el levante;

b) El pago electrónico de los derechos, impuestos, etc.;

c) La separación entre el levante y la determinación definitiva de los derechos de aduana, impuestos, tasas y cargas;

d) La gestión de riesgo mediante criterios de selectividad adecuados;

e) La auditoría posterior al despacho de aduana para asegurar el cumplimiento de la ley;

f) El establecimiento y publicación de los plazos medios de levante;

g) Las medidas de facilitación del comercio para los operadores autorizados;

h) Los envíos urgentes con un levante rápido;

i) La prioridad del levante y atención para con mercancías perecederas.

Siguiendo con la Sección I, el artículo 10 trata sobre "las formalidades en relación con la importación, la exportación y el tránsito" donde se desarrollan —al igual que en el artículo 7-9 medidas para la rápida circulación de mercancías y cooperación aduanera. Entre las medidas más relevantes tenemos: 
a) La reducción y simplificación de las formalidades y requisitos de documentación;

b) La utilización de normas internacionales;

c) El mantenimiento o implementación de una ventanilla única que permita a los comerciantes presentar a las autoridades $u$ organismos participantes la documentación y/o información exigida;

d) La no realización de inspecciones previas a la expedición en lo relacionado a clasificación arancelaria y la valoración aduanera;

e) La aceptación de los documentos sustentatorios de despacho en copias impresas y electrónicas;

f) La no obligatoriedad del recurso de AA para realizar trámites de importación, exportación y tránsito;

g) La permisibilidad de reexpedición de mercancías rechazadas.

Cabe señalar que la Sección II prevé disposiciones en materia de trato especial y diferenciado a los países en desarrollo y menos adelantados para la aplicación del AFC, con lo cual, el Perú notificó 29 disposiciones del acuerdo en categoría "A" en el año 2014; y la Sección III, constituida por los 2 últimos artículos del acuerdo, que contempla disposiciones institucionales y finales del acuerdo.

\section{CONCLUSIONES}

La regulación de todos los OCE era necesaria debido a proliferación de distintos operadores que no demostraban un eficiente desempeño ni con sus clientes ni con la Administración
Aduanera. Por ello, se realizó un estudio de mercado de los OCE y se incorporó a la normativa un sistema de gestión que mejorará el nivel de cumplimiento y desempeño de todos los sujetos de la obligación aduanera; en donde se renovarán autorizaciones y se establecerán facilidades y beneficios en virtud de su categoría como operador. No es que sea más flexible la Administración, sino que es más severa, minuciosa y cada vez más apoyada en sistemas digitales al momento de autorizar, categorizar o renovar autorizaciones. Además, ya era necesaria una norma que esté orientada a verdaderos profesionales del comercio exterior que implementen sistemas de gestión de calidad para un correcto desempeño de funciones, propias de su actividad.

Si bien es cierto que no se han suministrado datos estadísticos sobre tiempos de despacho en el presente artículo, se ha presentado la figura de 2 operadores que han cambiado en muy corto tiempo, de los cuales recién para el próximo año -2022- veremos cuántos de ellos lograrán renovar su autorización. Los mencionados cambios a los operadores dependen principalmente del gobierno y de la firma de acuerdos internacionales, en donde el intercambio de información, cooperación y asistencia técnica entre los países miembros facilita el comercio, reduce costos totales y beneficia a todos sus participantes. Es de mencionar que los costos de la aplicación de los acuerdos son inferiores a los beneficios que se logran cuando mejoramos los plazos del despacho de las mercancías y simplificamos las formalidades aduaneras. 